\title{
Effects of changing travel patterns on travel satisfaction: A focus on recently relocated residents
}

\author{
Jonas De Vos, Dick Ettema, Frank Witlox \\ Paper published in Travel Behaviour and Society: \\ De Vos, J., Ettema, D., Witlox, F., 2019. Effects of changing travel patterns on travel satisfaction: A \\ focus on recently relocated residents. Travel Behaviour and Society 16, 42-49.
}

\begin{abstract}
Previous studies indicate that travel satisfaction is affected by elements such as travel mode choice and trip duration. However, how people's satisfaction levels with travel adapt after changing their travel behaviour has not yet been analysed thoroughly. In this study we analyse travel satisfaction of 1,650 respondents who recently relocated to selected neighbourhoods in the city of Ghent (Belgium), and therefore changed their daily travel patterns (i.e., commute and leisure trips). Based on a two-step approach, i.e., a factor analysis followed by a cluster analysis, respondents are segmented into four clusters based on their changes in travel behaviour after they moved. Results indicate that especially clusters with respondents that decreased travel distance and duration, and increased the use of car alternatives have high levels of travel satisfaction, for both commute trips and leisure trips. Respondents from these clusters also indicated the highest levels of travel satisfaction improvements. This study provides additional motivation for policy makers and urban planners to convince more people to relocate to urban areas, or for densification and land use mixing of existing neighbourhoods, as this will not only result in more sustainable travel patterns, but also in more satisfying travel patterns.
\end{abstract}

Keywords: Travel satisfaction; Residential relocation; Travel behavior; Travel mode choice; Travel attitudes

\section{Introduction}

In the last decade, studies analysing how satisfied people are with their way of travelling have rapidly increased (e.g., De Vos \& Witlox, 2017). Most of these studies have examined which factors influence travel satisfaction levels. The main focus here has been on the effect of the chosen travel mode on travel satisfaction. Overall, these studies indicate that active travel results in high levels of travel satisfaction, while public transport use - bus use in particular - results in the lowest levels (e.g., De Vos et al., 2016; Morris \& Guerra, 2015b; Páez \& Whalen, 2010; Singleton, 2018; St-Louis et al., 2014). A second important focus has been on travel duration. Although some studies have indicated that travel time can have a positive utility (e.g., Jain \& Lyons, 2008; Ory \& Mokhtarian, 2005; Redmond \& Mokhtarian, 2001), studies focussing on travel satisfaction indicate that trip duration negatively impacts how people perceive their trip made (e.g., Higgins et al., 2018; Morris \& Guerra, 2015a; Zhu \& Fan, 2018a). Besides travel duration, far less attention has been given to the impact of travel distance. Some studies including travel distance into their analysis found positive effects of travel distance on travel satisfaction. Mokhtarian et al. (2015) indicate that longer trips may represent an escape from daily routine, while De Vos et al. (2016) suggest that people may partly confound their liking for a distant - mostly less common and perhaps more attractive - activity with their liking of the travel required to reach that activity. On the other hand, Handy and Thigpen (2018) found that long-distance 
(inter-urban) commuters are less satisfied with their trips compared to short-distance (intra-urban) commuters.

Attitudes can also affect travel satisfaction. A positive stance towards a certain mode positively affects travel satisfaction when using that mode (De Vos, 2018; De Vos et al., 2016; St-Louis et al., 2014; Ye \& Titheridge, 2017), just as travel-liking attitudes (e.g., appreciating travel time) positively influences travel satisfaction (De Vos \& Witlox, 2016; Ye \& Titheridge, 2017). People's residential location might also affect travel satisfaction, although studies found mixed results suggesting that the effect is context specific. Ye and Titheridge (2017), for instance, found no significant direct effects of the residential location on travel satisfaction, while De Vos and Witlox (2016) found somewhat higher levels of travel satisfaction for suburban residents compared to urban residents. Mokhtarian et al. (2015), on the other hand, indicate that urban residents tend to find trips less tiring, but also less pleasant compared to non-urban residents. De Vos et al. (2016) found that living in a neighbourhood stimulating the use of a preferred travel mode can positively affect travel satisfaction. Finally, travel satisfaction can also be affected by elements such as trip companionship (De Vos, 2017; Mokhtarian et al., 2015; Zhu \& Fan, 2018b), activities performed during travel (Ettema et al., 2012; Lyons et al., 2007; Tan et al., 2018), and weather conditions (e.g., Ettema et al. 2017; St-Louis et al., 2014). Of course, elements affecting travel satisfaction can considerable differ according to which travel mode has been chosen (see, for instance, Susilo \& Cats, 2014).

Only a limited number of studies have empirically analysed dynamics in travel satisfaction in relation to changing travel patterns. Abou-Zeid and Fujii (2016) and de Kruijf et al. (2018) state that a switch from car use to public transport and e-bike respectively (by giving car users financial compensation to use these respective modes) results in increased commute satisfaction. Schneider and Willman (2019) indicate that shorter distances and a shift to active travel result in higher levels of travel satisfaction when commuting to a new work or school location. In a review paper, Ettema et al. (2016) suggest that - based on existing literature - car users switching to public transport will experience lower levels of travel satisfaction, while a switch to active travel will most likely increase travel satisfaction. Although existing studies suggest that a mode switch will affect travel satisfaction, studies focussing on changes in travel satisfaction remain scarce. Besides changes in the used travel mode and travel distance, it is also possible that changes in travel duration and attitudes will influence travel satisfaction levels. These changes in travel patterns and attitudes are likely to occur in case of a residential relocation. A considerable number of studies has indicated that people moving to an urban-style neighbourhood walk, cycle and use public transport more often and travel less by car than in their previous neighbourhood, while opposite results can be found for people relocating to a more suburban-style neighbourhood (e.g., Aditjandra et al., 2016; Cao \& Ermagun, 2017; Krizek, 2003; Scheiner \& Holz-Rau, 2013). These modal shifts are partly explained by changes in travel distance. Moving to a compact, mixed-use urban area increases accessibility to destinations and mostly results in lower average distances, making it possible to walk and cycle more frequently. Moving to a low-density suburban neighbourhood - on the other hand - results in high average travel distances, often forcing people to travel by car. In most cases, moving to more urban neighbourhoods will therefore reduce household car possession, while moving to a suburban neighbourhood will increase car possession, further stimulating a modal shift (Aditjandra et al., 2016; Scheiner \& Holz-Rau, 2013). Two recent studies also indicate that people relocating to a new neighbourhood will improve their attitudes towards travel modes stimulated by the new built environment (De Vos et al., 2018; Wang \& Lin, 2017).

Since the choice of a residential location has important effects on people's travel behaviour, it is useful to analyse whether a residential relocation - and the accompanying changes in travel behaviour - will 
also affect travel satisfaction. We assume that this will indeed be the case, and to that end, we analyse which changes in travel behaviour have the biggest effects on travel satisfaction of people who recently relocated. The remainder of this paper is organised as follows. Section 2 discusses the used data, while the analysis - segmenting respondents into four clusters - is provided in Section 3. Section 4 provides results on travel satisfaction (changes) of the clustered respondents, while discussion and conclusions are provided in Section 5 .

\section{Data}

For this study we use data from a 2017 travel survey of recently relocated people within the city of Ghent, Belgium (260,000 inhabitants). Within the city of Ghent, we selected two internally homogeneous sets of urban and suburban neighbourhoods. The selected urban neighbourhoods are compact, mixed-use areas with good public transport services, while the suburban neighbourhoods are mostly low-density, single-use areas with good car accessibility and limited public transport facilities. In sum, the urban neighbourhoods stimulate active travel and public transport, while the suburban neighbourhoods stimulate car use. In February and March 2017, 9,979 letters with an invitation to participate in an online survey were distributed to all households that recently (within the last two years) relocated to the selected neighbourhoods. In the end, 1,842 adults participated, of which 1,650 respondents - who completed the survey - were used in this study (resulting in a response rate of $16.5 \%)$. For more details on the neighbourhood selection and sampling recruitment, see De Vos et al. (2018).

Respondents in our sample are relatively young and mostly live in urban neighbourhoods (Table 1). This is not surprising as young adults are - compared to older adults - more likely to relocate due to a considerable amount of life events taking place during early adulthood (e.g., entry into the labour market, formation of a household with partner, having children). In contrast to young adults - and consequently households without children - being overrepresented, other socio-demographics of our respondents (e.g., income, gender, household composition) are comparable to the total population of the selected neighbourhoods (https://gent.buurtmonitor.be/). Although we cannot claim to have a fully representative sample of the total population of selected neighbourhoods - or of all people recently relocating to these neighbourhoods - we do have a relatively large sample size, making it possible to estimate relationships with ample confidence. ${ }^{1}$ The high share of urban residents can be explained by the fact that residential mobility is higher in urban neighbourhoods than in suburban neighbourhoods. Based on the total population of the selected neighbourhoods and the people moving to these neighbourhoods in the last two years, we found that - for our sample - residential mobility is 2.77 times higher in urban neighbourhoods than in suburban neighbourhoods.

\footnotetext{
1 Although our sample might not be representative for the total population of the selected neighbourhoods, it is probably more representative for the total group of people relocating to these neighbourhoods (since we invited all residents that recently moved to the selected neighbourhoods). However, since we do not have information on the socio-demographics of all movers, we cannot claim to have a representative sample of relocated residents.
} 
Table 1. respondents' socio-demographic characteristics $(\mathrm{N}=1,650)$

\begin{tabular}{|c|c|}
\hline & Total \\
\hline Personal characteristics & $\%$ \\
\hline \multicolumn{2}{|l|}{ Age distribution } \\
\hline $18-29$ & 49.5 \\
\hline $30-44$ & 29.1 \\
\hline $45-59$ & 13.4 \\
\hline $60+$ & 8.0 \\
\hline \multicolumn{2}{|l|}{ Gender } \\
\hline Female & 47.9 \\
\hline Male & 52.1 \\
\hline \multicolumn{2}{|l|}{ Education } \\
\hline High education (University (college) degree) & 77.2 \\
\hline \multicolumn{2}{|l|}{ Job status } \\
\hline Full time & 72.8 \\
\hline Part time & 10.7 \\
\hline Unemployed & 6.4 \\
\hline Retired & 6.9 \\
\hline Student & 3.2 \\
\hline \multicolumn{2}{|l|}{ Household characteristics } \\
\hline \multicolumn{2}{|l|}{ Household composition } \\
\hline Single & 29.9 \\
\hline Single parent & 5.9 \\
\hline Couple without children & 37.3 \\
\hline Couple with children & 14.6 \\
\hline Other (e.g., living with parents, with friends) & 12.3 \\
\hline \multicolumn{2}{|l|}{ Household net income/month } \\
\hline Low income (<2000 euro) & 38.5 \\
\hline Medium income (2000 - 3,499 euro) & 33.9 \\
\hline High income (3500+ euro) & 27.6 \\
\hline \multicolumn{2}{|l|}{ Residential location } \\
\hline Urban neighbourhood & 67.4 \\
\hline Suburban neighbourhood & 32.6 \\
\hline \multicolumn{2}{|l|}{ Household car ownership } \\
\hline 0 & 25.5 \\
\hline 1 & 54.3 \\
\hline$>1$ & 20.2 \\
\hline
\end{tabular}

\subsection{Key variables}

\subsubsection{Changes in respondents' travel behaviour}

In the survey we asked respondents to which extent they changed their travel behaviour - and elements linked to travel behaviour - after they moved. For both commute trips and leisure trips, respondents were asked to indicate to what extent their frequency of mode use (i.e., car use, bus/tram use, train use, cycling, and walking), average travel distance, and average travel duration changed after they relocated, on a five-point scale going from -2 (strongly decreased) to +2 (strongly increased). We also asked respondents to what extent their attitudes towards travel in general, and travel modes in particular changed after their move, again on a five-point scale going from -2 (strongly worsened) to +2 (strongly improved). Finally, we also asked information regarding changes in the built environment and changes in household car possession, two elements affecting people's travel behaviour. We asked respondents to indicate to what extent their current neighbourhood is more or less urbanised compared to their previous neighbourhood (on a scale from -2 (far less urbanised) to +2 (far more urbanised)), while changes in household car possession were measured by taking the difference 
between current car possession and car possession before the relocation. Results from respondents' self-reported changes in travel behaviour indicate that - on average - travel distance, travel duration and car frequency decrease while walking and cycling increase, for both commute and leisure trips (See Table 2). These changes especially occur for respondents moving to urban neighbourhoods; opposite changes are only found for suburban residents previously living in more urbanised neighbourhoods (see, De Vos et al., 2018). This can be partly explained by the fact that $27.9 \%$ of the respondents relocated to live closer to their job, and $48.3 \%$ of the respondents indicate that proximity of leisure activities was important to very important in the choice where to live. Results also indicate that respondents' travel attitudes to a certain extent change, becoming more in line with the travel behaviour stimulated by the new residential neighbourhood (for detailed results on changes in respondents' travel behaviour and attitudes, see De Vos et al., 2018).

\subsubsection{Travel satisfaction (changes)}

We measured respondents' satisfaction with travel for both commute trips and leisure trips by asking them to what extent they agree - on a scale from 1 (totally disagree) to 5 (totally agree) - with the following six statements:

- I am satisfied with my commute trips (leisure trips);

- When I think about my commute trips (leisure trips), the positive aspects outweigh the negative;

- I do not want to change anything about my commute trips (leisure trips);

- My commute trips (leisure trips) provide me with positive feelings;

- My commute trips (leisure trips) go well;

- I could not imagine my commute trips (leisure trips) to go any better.

The internal consistency (i.e., the average inter-item correlation) of the six items measuring satisfaction with commute trips and the six items measuring satisfaction with leisure trips are high (Cronbach's alphas are 0.94 and 0.93 , respectively). As a result, reliable variables representing satisfaction with commute trips and leisure trips were created by averaging the scores on the six statements concerning commute trip satisfaction and leisure trip satisfaction, respectively. Respondents seem somewhat less satisfied with their commute trips than with their leisure trips (i.e., average scores are 3.57 and 3.71, respectively), possibly since they might - to a certain extent confound their liking for the activity at the destination of the trip with satisfaction with the trip towards this activity. As a result, trips to non-mandatory (leisure) activities are often perceived more positively compared to trips to mandatory (work) activities (Ettema et al., 2013; Mokhtarian et al., 2015; Ory \& Mokhtarian, 2005; Mokhtarian \& Salomon, 2001). Of course, it might also be possible that trip characteristics (e.g., level of congestion) are less beneficial for travel satisfaction during periods that people mostly travel to and from work (i.e., peak hours). Table 2 shows that travel satisfaction levels are highest for respondents that have decreased car use, travel distance and duration, and those that increased walking and cycling. For commute trips, decreasing levels of public transport use seem to positively affect commute satisfaction. 
Table 2. Travel satisfaction of commute trips (top; $N=1,430$ ) and leisure trips (bottom; $N=1,650$ ) according to changes in travel mode, distance and duration (row percentages in brackets). ${ }^{2}$

\begin{tabular}{lccccc}
\hline & $\begin{array}{c}\text { Strongly } \\
\text { decreased }\end{array}$ & Decreased & $\begin{array}{c}\text { Remained } \\
\text { stable }\end{array}$ & Increased & $\begin{array}{c}\text { Strongly } \\
\text { increased }\end{array}$ \\
\hline \multicolumn{1}{c}{ Commute trips } & & & & & \\
Car use & $4.06(21.6 \%)$ & $3.72(10.5 \%)$ & $3.47(51.5 \%)$ & $3.41(8.5 \%)$ & $3.14(7.9 \%)$ \\
Bus/tram use & $3.70(16.0 \%)$ & $3.66(10.8 \%)$ & $3.53(55.2 \%)$ & $3.58(13.0 \%)$ & $3.46(5.0 \%)$ \\
Train use & $3.78(19.2 \%)$ & $3.72(7.5 \%)$ & $3.57(63.2 \%)$ & $3.32(5.8 \%)$ & $2.96(4.3 \%)$ \\
Cycling & $3.32(11.1 \%)$ & $3.42(8.3 \%)$ & $3.49(48.6 \%)$ & $3.76(14.7 \%)$ & $3.95(17.3 \%)$ \\
Walking & $3.45(12.7 \%)$ & $3.45(6.9 \%)$ & $3.51(55.2 \%)$ & $3.68(13.9 \%)$ & $4.04(11.3 \%)$ \\
Distance & $4.19(26.6 \%)$ & $3.62(16.9 \%)$ & $3.46(33.5 \%)$ & $3.34(16.0 \%)$ & $2.78(6.9 \%)$ \\
Duration & $4.23(26.4 \%)$ & $3.62(6.1 \%)$ & $3.45(32.8 \%)$ & $3.36(15.9 \%)$ & $2.63(6.1 \%)$ \\
\hline \multicolumn{1}{c}{ Leisure trips } & & & & \\
Car use & $3.94(17.1 \%)$ & $3.70(16.8 \%)$ & $3.73(49.0 \%)$ & $3.58(12.2 \%)$ & $3.33(4.8 \%)$ \\
Bus/tram use & $3.74(7.6 \%)$ & $3.63(12.4 \%)$ & $3.73(52.3 \%)$ & $3.69(21.9 \%)$ & $3.83(5.8 \%)$ \\
Train use & $3.74(10.1 \%)$ & $3.59(10.3 \%)$ & $3.72(66.4 \%)$ & $3.81(11.1 \%)$ & $3.58(2.2 \%)$ \\
Cycling & $3.71(7.2 \%)$ & $3.52(10.6 \%)$ & $3.74(48.5 \%)$ & $3.67(21.1 \%)$ & $3.90(12.7 \%)$ \\
Walking & $3.49(5.0 \%)$ & $3.50(9.3 \%)$ & $3.69(44.0 \%)$ & $3.72(25.7 \%)$ & $4.02(16.0 \%)$ \\
Distance & $4.04(16.0 \%)$ & $3.85(22.9 \%)$ & $3.74(40.8 \%)$ & $3.40(17.3 \%)$ & $2.99(3.1 \%)$ \\
Duration & $4.18(14.7 \%)$ & $3.84(24.7 \%)$ & $3.74(40.6 \%)$ & $3.38(17.4 \%)$ & $2.77(2.6 \%)$ \\
\hline
\end{tabular}

We also asked respondents to indicate how satisfied they are now with their commute and leisure trips compared to before their relocation, on a five-point scale from -2 (far less satisfied) to +2 (far more satisfied). Overall, respondents indicate that their travel satisfaction slightly increased since they moved (average scores of 0.44 and 0.40 for commute trips and leisure trips, respectively). For commute trips, $38.4 \%$ of the respondents indicate no changes in travel satisfaction, $11.4 \%$ report decreased satisfaction levels (3.3\% being far less satisfied, $8.1 \%$ being less satisfied), while $36.8 \%$ indicate to be more satisfied ( $21.3 \%$ being more satisfied, $15.5 \%$ being far more satisfied). For leisure trips, almost half of the respondents (49.2\%) report no changes in travel satisfaction; $10.8 \%$ indicate to be less satisfied (1.3\% being far less satisfied; $9.5 \%$ being less satisfied), $40.0 \%$ indicate to be more satisfied (27.3\% being more satisfied, $12.7 \%$ being far more satisfied). These results are in line with studies suggesting that people will try to live in a neighbourhood enabling them to have satisfying trips (Cao \& Ettema, 2014; De Vos \& Witlox, 2016). This suggestion is also supported by the fact that $72.1 \%$ of the respondents indicates that mobility aspects were an important to very important element in the residential location choice, indicating that people try to choose a neighbourhood resulting in a perceived improvement of travel patterns. In other words, results are in line with the (transportrelated) residential self-selection hypothesis (see, for instance, Cao et al., 2009), indicating that people choose a residential neighbourhood based on travel needs and preferences.

\section{Analysis}

Since a residential relocation can simultaneously affect multiple travel-related elements (e.g., moving to a more urban neighbourhood might reduce travel distances, household car possession and car use, while increasing active travel and public transport use), it is more interesting to analyse changing patterns in travel behaviour, instead of looking at all changing elements separately. We therefore perform a two-step segmentation of the recently moved respondents. First, we applied a factor analysis on respondents' self-reported changes in travel behaviour after they moved, resulting in six

\footnotetext{
${ }^{2}$ Since unemployed and retired respondents do not perform commute trips, the number of respondents in the analyses of commute trips is lower than the respondents used in the analyses for leisure trips (i.e., 1,430 versus $1,650)$.
} 
factors. In a second stage, we carried out a cluster analysis on these six factors to segment recently relocated respondents into distinct groups according to how they changed their travel behaviour, resulting in four clusters of respondents. Although relatively rare, this two-step method - i.e., factor analysis followed by a cluster analysis - has occasionally been applied in travel behaviour studies (e.g., De Vos et al., 2016; Grisé \& El-Geneidy, 2018).

\subsection{Factor analysis}

To get insights into how changes in travel-related elements are related with each other, we factor analysed the 21 variables referring to changes in mode frequency (of commute and leisure trips), changes in travel attitudes, changes in trip duration and distance (of commute and leisure trips), changes in the level of urbanisation, and changes in car possession. This factor analysis (principal axis factoring, promax rotation) resulted in six factors (mainly based on eigenvalues and interpretability), explaining $61.2 \%$ of total variance (Table 3 ). The first two factors relate to increases in travel distance and duration, of commute trips and leisure trips respectively. The third factor refers to increased cycling and improved attitudes towards cycling. The fourth factor relates to increased use of public transport and - to a limited extent - improved attitudes towards public transport use. The fifth cluster is related to increased use of active travel and public transport and decreased car use. This factor is also - to a certain degree - linked with a (perceived) increase in the level of urbanisation. The final factor refers to improved attitudes towards travel in general, but also to all travel modes separately. 
Table 3. Changing travel behaviour factors ${ }^{3}$

\begin{tabular}{|c|c|c|}
\hline Factor (explained variance; eigenvalue) & Self-reported change in travel-related elements & Loading \\
\hline \multirow{2}{*}{$\begin{array}{l}\text { 1. Increase in commute distance/duration } \\
\qquad(21.9 \% ; 4.38)\end{array}$} & Change in commute distance & 0.92 \\
\hline & Change in commute duration & 0.92 \\
\hline \multirow{3}{*}{$\begin{array}{l}\text { 2. Increase in leisure trip distance/duration } \\
\qquad(11.5 \% ; 2.30)\end{array}$} & Change in leisure trip distance & 0.92 \\
\hline & Change in leisure trip duration & 0.90 \\
\hline & Change in cycling for commuting & 0.76 \\
\hline \multirow{3}{*}{$\begin{array}{l}\text { 3. Increased cycling (attitudes) } \\
\qquad(8.5 \% ; 1.71)\end{array}$} & Change in cycling for leisure trips & 0.58 \\
\hline & Change in attitudes towards cycling & 0.45 \\
\hline & Change in car use for commuting & -0.41 \\
\hline \multirow{7}{*}{$\begin{array}{l}\text { 4. Increased public transport (attitudes) } \\
\qquad(7.1 \% ; 1.43)\end{array}$} & Change in bus/tram use for commuting & 0.65 \\
\hline & Change in train use for commuting & 0.53 \\
\hline & Change in bus/tram for leisure trips & 0.45 \\
\hline & Change in train use for leisure trips & 0.33 \\
\hline & Change in attitude towards public transport & 0.28 \\
\hline & Change in car use for commuting & -0.28 \\
\hline & Change in walking for commuting & 0.26 \\
\hline \multirow{6}{*}{$\begin{array}{l}\text { 5. Increased multimodality for leisure trips } \\
\qquad(6.6 \% ; 1.32)\end{array}$} & Change in walking for leisure trips & 0.76 \\
\hline & Change in car use for leisure trips & -0.48 \\
\hline & Change in cycling for leisure trips & 0.41 \\
\hline & Change in bus/tram use for leisure trips & 0.35 \\
\hline & Change in level of urbanisation & 0.32 \\
\hline & Change in train use for leisure trips & 0.32 \\
\hline \multirow{5}{*}{$\begin{array}{l}\text { 6. Improved travel attitudes } \\
\qquad(5.6 \% ; 1.12)\end{array}$} & Change in attitudes towards travel liking & 0.52 \\
\hline & Change in attitudes towards public transport use & 0.52 \\
\hline & Change in attitudes towards walking & 0.50 \\
\hline & Change in attitudes towards cycling & 0.47 \\
\hline & Change in attitudes towards car use & 0.37 \\
\hline
\end{tabular}

\subsection{Cluster analysis}

In a second step, we performed a k-means cluster analysis using the six factors generated in the factor analysis. This technique classifies respondents into clusters, where (i) the differences between each cluster and (ii) similarities between members of the same cluster are maximised. To determine the most appropriate number of clusters, we evaluated the outcomes of cluster analyses with three to eight clusters. In the end, the four-cluster solution was chosen, mainly based on the interpretability of the clusters. The four clusters are presented in Figure 1, where the bars represent the relative value of the factors described in Table 3. In the following sections, we will describe the four clusters in detail.

\footnotetext{
${ }^{3}$ In order to improve readability, only self-reported changes in travel-related elements with a factor loading of at least 0.25 in magnitude are shown. Since 'change in car possession' did not load strongly on one of the factors (i.e., a factor loading of at least 0.25 in magnitude), we have removed this variable from the factor analysis.
} 


\begin{tabular}{cccc}
$\begin{array}{c}\text { Decrease in (leisure) trip } \\
\text { distance/duration; increased } \\
\text { multimodality (attitudes) }\end{array}$ & $\begin{array}{c}\text { Decrease in (commute) } \\
\text { distance/duration; stable } \\
\text { mode frequency }\end{array}$ & $\begin{array}{c}\text { Increase in travel } \\
\text { distance/duration; stable } \\
\text { mode frequency }\end{array}$ & $\begin{array}{c}\text { Increase in travel } \\
\text { intance/duration; decrease } \\
\text { in use of car alternatives }\end{array}$ \\
\cline { 3 - 4 } & & &
\end{tabular}

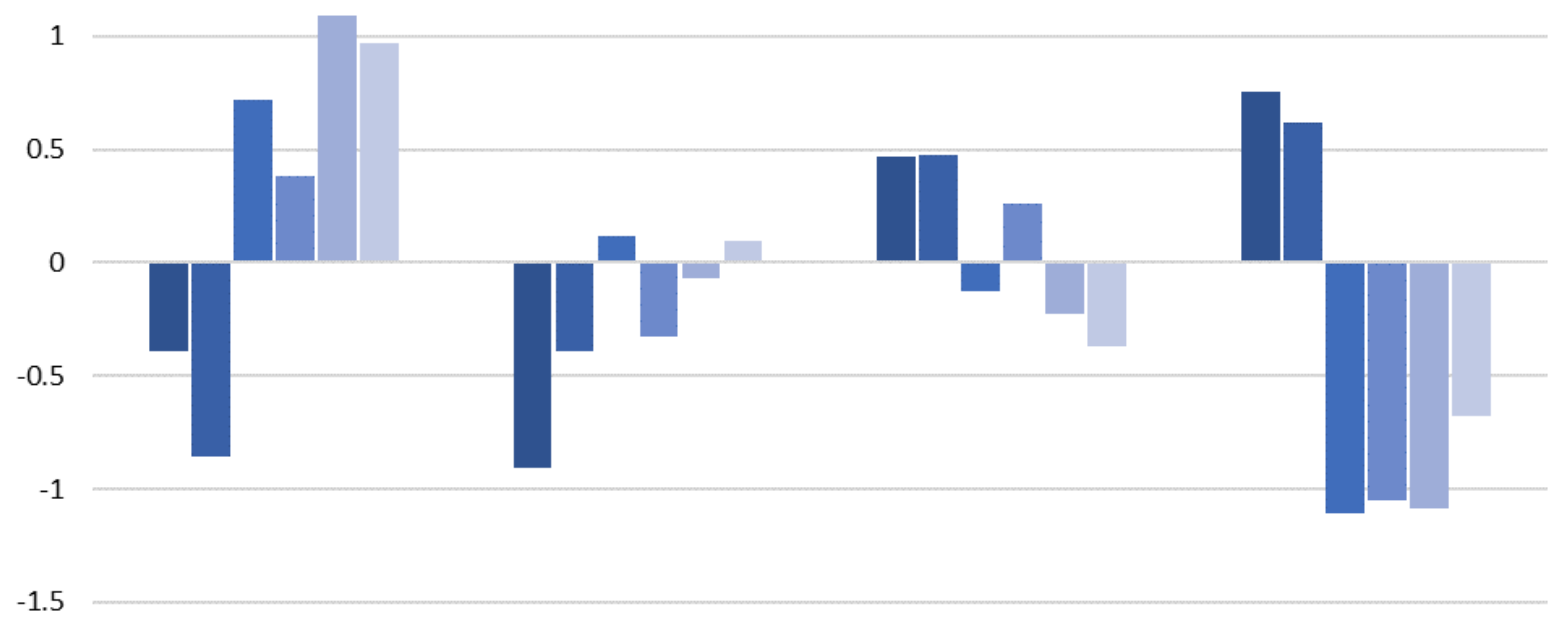
-1. Increase in commute distance/duration
- 2. Increase in leisure trip distance/duration
a. Increased cycling (attitudes)
4. Increased public transport (attitudes)
5. Increased multimodality for leisure trips
6. Improved travel attitudes

Figure 1. Segmentation of recent movers derived from factor and cluster analysis.

\subsubsection{Cluster 1: Decrease in (leisure) trip distance/duration; increased multimodality (attitudes)}

Respondents in the first cluster ( $\mathrm{N}=370 ; 22.4 \%$ of the sample) have - after their residential relocation - reduced their travel distance and duration (especially of leisure trips), increased their use of car alternatives (possibly due to increased levels of urbanisation of the new neighbourhood), and improved their travel attitudes. In socio-demographic terms, this cluster contains the largest share of women (56.2\%), while the average age is - compared to the total sample - relatively high ( 36.4 years old). This cluster has the lowest share of (part-time or full-time) working respondents $(78.4 \%)$, while $78.4 \%$ has a university (college) degree. Single (parents) are well-represented (41.1\%), while $27.0 \%$ of the respondents lives in a household with a high income ( $\geq € 3,500$ net/month), and $20.5 \%$ in a household with child(ren). The largest share of these respondents (i.e., $84.3 \%$ ) live in urban neighbourhoods, while almost one third lives in a household without a car. In terms of current travel patterns, respondents in this cluster travel least by car, and walk, cycle and use bus/tram most frequently for both commute and leisure trips. Commute distance and duration are in between values of other clusters (Table 4).

\subsubsection{Cluster 2: Decrease in (commute) distance/duration; stable mode frequency}

Respondents in the second cluster ( $N=369 ; 22.4 \%$ of the sample) have mainly reduced travel distance and duration of commute trips. Members of this cluster also reduced distance and duration of leisure trips to a certain extent, while also public transport use (and accompanying attitudes) has decreased. Overall, mode frequency remained rather stable. Respondents in this cluster are on average younger than members of other clusters (i.e., 32.5 years old). Slightly less than half of the cluster members are women, while $\mathbf{8 7 . 0 \%}$ is (partly or fully) employed. This cluster has the highest share of highly educated respondents $(81.6 \%)$, a relatively high share of singles/single parents $(40.1 \%)$, and the lowest share of 
respondents living in a household with a high income (23.9\%) or a household with child(ren) (16.3\%). This cluster has a high share of urban respondents (78.9\%), and about one in four lives in a household without a car. Respondents in this cluster do not have a clear choice of travel mode, although frequent car use is relatively low and frequent walking and cycling are relatively high. Average commute distance and duration are lowest for this cluster (Table 4).

\subsubsection{Cluster 3: Increase in travel distance/duration; stable mode frequency}

Respondents in the third cluster ( $N=715 ; 43.3 \%$ of the sample) have witnessed an increase in their travel distance and duration, for both commute and leisure trips. In terms of travel mode choice, no considerable changes occurred, although attitudes towards travel (modes) seem to have deteriorated (though less compared to cluster 4). Somewhat more than half of the respondents in this cluster are men, and living in urban neighbourhoods; $33.1 \%$ is single (parent), $75.9 \%$ is highly educated, $82.4 \%$ is employed, $20.8 \%$ lives in a household with child(ren), and the average age is 36.6 years old. Slightly more than one in four members of this cluster lives in a household with a high income and a household without a car. Respondents in this cluster do not have a clear choice of travel mode, although this cluster is characterised by the highest share of frequent train use for commuting (25.6\%). Frequent car use, walking and cycling is by and large comparable with other clusters. Members in this clusters have relatively long average commute distances and durations (Table 4).

\subsubsection{Cluster 4: Increase in travel distance/duration; decrease in use of car alternatives}

Respondents in the fourth cluster ( $N=196 ; 11.9 \%$ of the sample) have increased their travel distance and duration of both commute trips and leisure trips. Furthermore, members of this cluster have also witnessed a clear reduction in walking, cycling, and public transport use (possibly due to decreased levels of urbanisation of the new neighbourhood), just as a deterioration of attitudes towards these modes. Respondents in this cluster are on average 33.5 years old and $45.4 \%$ are women. This cluster has the highest share of respondents being employed (90.3\%) and respondents living in a high-income household (30.1\%) or household with child(ren) (29.1\%), and the lowest share of respondents living in a household without a car (5.6\%), respondents being single (parent) (27.6\%), and highly-educated respondents $(71.4 \%)$. This is the only cluster with more suburban residents compared to urban residents ( $57.7 \%$ versus $42.3 \%$, respectively). Members of this cluster travel most frequently by car, and walk, cycle and use public transport least frequently; commuting distance and duration are relatively high (Table 4). 
Table 4. Cluster members' socio-demographics and travel characteristics ${ }^{4}$

\begin{tabular}{|c|c|c|c|c|}
\hline & Cluster 1 & Cluster 2 & Cluster 3 & Cluster 4 \\
\hline \multicolumn{5}{|l|}{ Socio-demographics } \\
\hline Age (years) & 36.4 & 32.5 & 36.6 & 33.5 \\
\hline Gender (women) & $56.2 \%$ & $49.3 \%$ & $43.5 \%$ & $45.4 \%$ \\
\hline High education (university (college) degree) & $78.4 \%$ & $81.6 \%$ & $75.9 \%$ & $71.4 \%$ \\
\hline Employed (full time or part time) & $78.4 \%$ & $87.0 \%$ & $82.4 \%$ & $90.3 \%$ \\
\hline High household net income/month $(\geq € 3,500)$ & $27.0 \%$ & $23.9 \%$ & $29.0 \%$ & $30.1 \%$ \\
\hline Single (parent) & $41.1 \%$ & $40.1 \%$ & $33.1 \%$ & $27.6 \%$ \\
\hline Household with child(ren) & $20.5 \%$ & $16.3 \%$ & $20.8 \%$ & $29.1 \%$ \\
\hline Urban neighbourhood & $84.3 \%$ & $78.9 \%$ & $59.7 \%$ & $42.3 \%$ \\
\hline Household with car(s) & $68.1 \%$ & $74.3 \%$ & $72.4 \%$ & $94.4 \%$ \\
\hline \multicolumn{5}{|l|}{ Travel characteristics } \\
\hline Frequent car use (commute) & $28.2 \%$ & $35.2 \%$ & $34.8 \%$ & $72.9 \%$ \\
\hline Frequent bus/tram use (commute) & $16.5 \%$ & $8.1 \%$ & $13.4 \%$ & $8.3 \%$ \\
\hline Frequent train use (commute) & $22.3 \%$ & $13.8 \%$ & $25.6 \%$ & $8.9 \%$ \\
\hline Frequent cycling (commute) & $57.1 \%$ & $51.9 \%$ & $47.5 \%$ & $19.9 \%$ \\
\hline Frequent walking (commute) & $36.7 \%$ & $28.9 \%$ & $23.5 \%$ & $9.4 \%$ \\
\hline Frequent car use (leisure) & $21.6 \%$ & $36.3 \%$ & $39.5 \%$ & $66.8 \%$ \\
\hline Frequent bus/tram use (leisure) & $20.6 \%$ & $12.7 \%$ & $15.7 \%$ & $6.6 \%$ \\
\hline Frequent train use (leisure) & $11.1 \%$ & $9.2 \%$ & $10.7 \%$ & $4.1 \%$ \\
\hline Frequent cycling (leisure) & $66.2 \%$ & $53.7 \%$ & $53.9 \%$ & $33.2 \%$ \\
\hline Frequent walking (leisure) & $63.5 \%$ & $40.4 \%$ & $40.3 \%$ & $23.9 \%$ \\
\hline Commute distance $(\mathrm{km})$ & 21.5 & 13.2 & 26.4 & 27.0 \\
\hline Commute duration (min.) & 30.1 & 20.1 & 36.0 & 31.9 \\
\hline $\mathrm{N}$ & 370 & 369 & 715 & 196 \\
\hline$\%$ & 22.4 & 22.4 & 43.3 & 11.9 \\
\hline
\end{tabular}

\section{Travel satisfaction (changes) of recently relocated residents}

Table 5 shows average travel satisfaction levels - of both commute trips and leisure trips - for the four clusters and to what extent they differ from each other. For commute trips, clusters 1 and 2 have significantly higher levels of travel satisfaction than cluster 3 , and especially cluster 4 , which has significantly lower levels of travel satisfaction compared to other clusters. Clusters of respondents that have decreased their travel distance and duration (especially those of commute trips) have the highest levels of commute satisfaction, while clusters of respondents where travel distance/duration has increased have the lowest levels of commute satisfaction, especially in combination with decreased walking, cycling and public transport use (i.e., cluster 4). Satisfaction with leisure trips is highest for cluster 1, where respondents have decreased travel distance and duration, especially of leisure trips, increased active travel and public transport use, and improved travel attitudes. Cluster 2 has the second highest levels of satisfaction with leisure trips, followed by cluster 3. Cluster 4, i.e., the group of respondents that have increased travel distance and duration accompanied by reduced walking, cycling and public transport use, has significantly lower levels of satisfaction with leisure trips compared to the other clusters. In sum, results indicate that clusters of respondents reducing travel distance and duration, in combination with decreased car use and increased public transport use and active travel have the highest levels of travel satisfaction.

\footnotetext{
${ }^{4}$ On a scale from 1 (never) to 5 (always), respondents were asked to indicate how often they currently use various travel modes (i.e., car, bus/tram; train; cycling; walking) for both commute trips and leisure trips. Respondents indicating 4 or 5 on this scale were labeled as frequent mode users.
} 
Table 5. Average travel satisfaction scores for commute trips (left; $N=1,430$ ) and leisure trips (right; $N$ $=1,650)$, and $p$-values of a one-way ANOVA with post-hoc multiple comparison analysis using the Least Significant Difference (LSD) method (bold = significant at $p<0.05$ )

\begin{tabular}{lcccc|ccccc}
\hline \multicolumn{5}{c}{ Commute trips } & \multicolumn{5}{c}{ Leisure trips } \\
& Avg. & 1. & 2. & 3. & & Avg. & 1. & 2. & 3. \\
\hline 1. Cluster 1 & 3.78 & & & & 1. Cluster 1 & 4.01 & & & \\
2. Cluster 2 & 3.90 & 0.14 & & & 2. Cluster 2 & 3.73 & $\mathbf{0 . 0 0}$ & & \\
3. Cluster 3 & 3.39 & $\mathbf{0 . 0 0}$ & $\mathbf{0 . 0 0}$ & & 3. Cluster 3 & 3.63 & $\mathbf{0 . 0 0}$ & 0.06 & \\
4. Cluster 4 & 3.20 & $\mathbf{0 . 0 0}$ & $\mathbf{0 . 0 0}$ & $\mathbf{0 . 0 3}$ & 4. Cluster 4 & 3.45 & $\mathbf{0 . 0 0}$ & $\mathbf{0 . 0 0}$ & $\mathbf{0 . 0 0}$ \\
\hline
\end{tabular}

Changes in travel satisfaction following a residential relocation also differ between the four clusters. Figure 2 shows the percentages of respondents within clusters indicating a change in the level of travel satisfaction since they relocated (on a five-point scale going from far less satisfied to far more satisfied). In analogy with the average travel satisfaction scores shown in Table 5, we find that travel satisfaction increased most for cluster 2 for commute trips, and most for cluster 1 for leisure trips. In cluster 4 , the group of respondents indicating a decrease in commute satisfaction is somewhat larger than the group indicating an increase in commute satisfaction, while the groups indicating decreasing and increasing levels of satisfaction with leisure trips have a similar size. The largest group of respondents from cluster 3 indicates no change in satisfaction with commute and leisure trips since their relocation. This might be explained by the fact that members of this cluster witnessed only limited changes in their travel patterns.

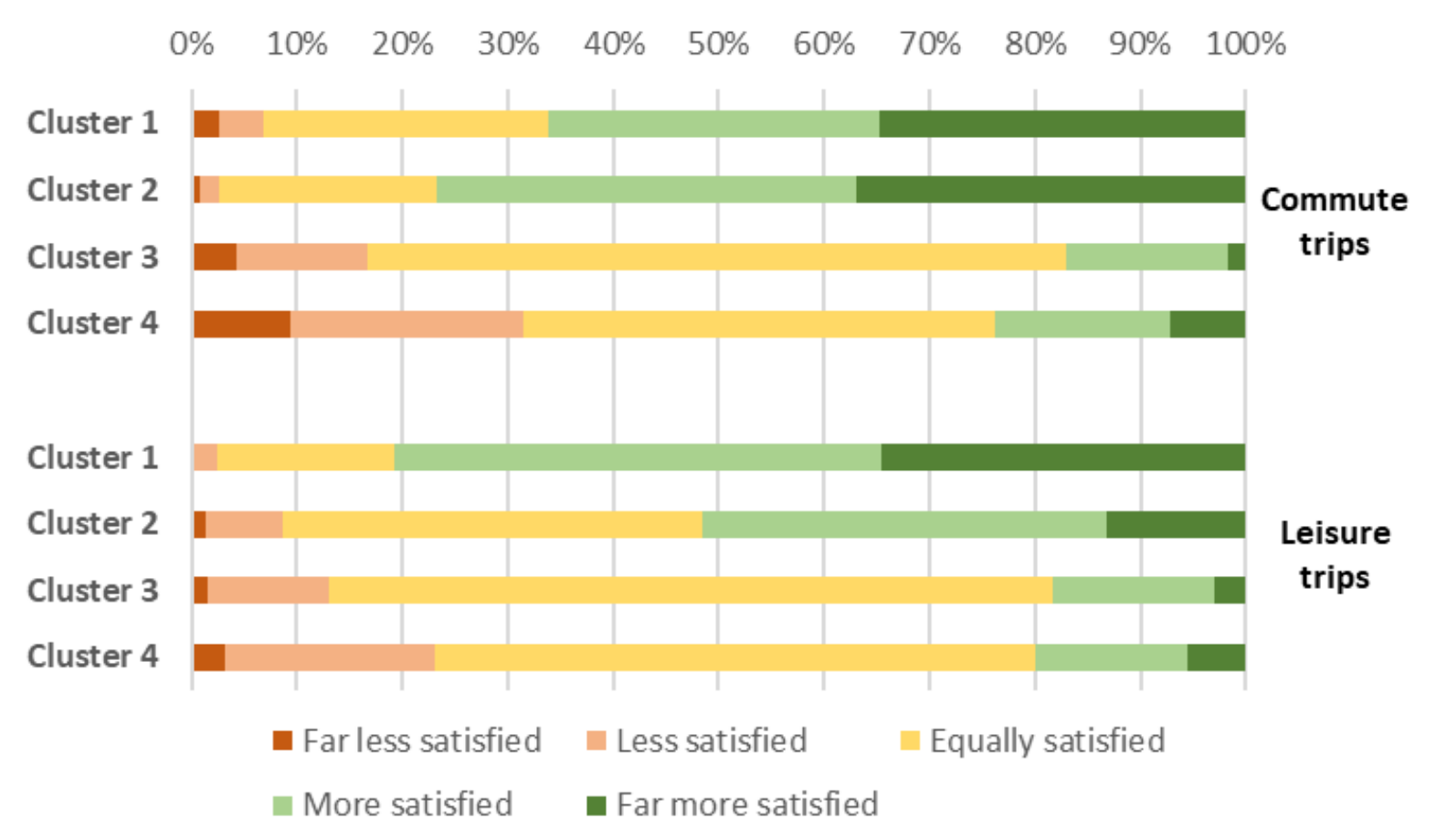

Figure 2. Self-reported changes in travel satisfaction

The found levels of travel satisfaction (changes) seem in line with existing studies indicating that active travel and short trip duration/distance result in satisfied travellers (e.g., De Vos et al., 2016; Handy \& Thigpen, 2018; Morris \& Guerra, 2015a, 2015b; St-Louis et al., 2014). However, most of these studies did not analyse variations in travel patterns. Therefore, low levels of satisfaction using a certain mode might be partly explained by certain levels of captivity (e.g., car lovers forced to use public transport 
because they cannot afford a car), while low satisfaction levels of long trips might be partly explained by people being forced to travel long distances (e.g., due to living far away from their job) although perceiving travel time as wasted time. Since our study analysed travel satisfaction before and after a relocation, we have analysed travel satisfaction of respondents' different travel patterns, therefore partly circumventing the problem of 'forced' travel patterns. The fact that high/improved travel satisfaction levels can be found for people travelling more active and shorter trips, suggest that walking and cycling are inherently more enjoyable than motorised travel (possibly due to the physical activity it provides), and that short travel distances/durations are most desired (possible because it offers people more time to perform valued social/leisure activities).

\section{Discussion and conclusion}

In this study we have segmented recently relocated residents based on changes in their travel behaviour. By performing a factor analysis followed by a cluster analysis, respondents were grouped into four clusters. Travel satisfaction levels - for both commute trips and leisure trips - clearly differ between members of these four clusters. Clusters characterised by reduced travel distance and duration, increased walking, cycling and public transport use, and decreased car use have the highest average travel satisfaction levels. Respondents in these clusters also often indicate an increase in their travel satisfaction since they relocated. On the other hand, clusters characterised by increased travel distance and duration, increased car use, and decreased active travel and public transport use have the lowest average travel satisfaction levels. Respondents in these clusters mainly indicate no clear change in their travel satisfaction since they relocated.

Results from this study indicate that moving to a more urban-style neighbourhood (mainly respondents in cluster 1 ) is not only linked with lower car use and reduced travel distance/duration, but also results in high/improved levels of travel satisfaction. On the other hand, moving to a more suburban-style neighbourhood (mainly respondents in cluster 4), related with increased travel distance/duration and increased car use, results in relatively low levels of travel satisfaction (improvements). In sum, moving to a compact, mixed use neighbourhood might not only result in sustainable travel patterns, but also in satisfying travel patterns, which in turn can improve people's subjective well-being and quality of life (e.g., De Vos, 2017; De Vos et al., 2013). This can be regarded as an extra motivation for policy makers to persuade people to live/relocate to urban environments, or to create urban-style neighbourhoods (by creating new compact, mixed-use neighbourhoods, or by densification and land use mixing in existing neighbourhoods). Due to self-selection effects, improving public transport services and infrastructure for active travel in urban areas might convince people to move to urban neighbourhoods as it might provide them with more satisfying travel patterns.

We want to highlight the novelty of our study that - to our knowledge - is one of the first studies analysing travel satisfaction effects of changes in people's travel behaviour (due to a residential relocation). It should be noted that results from this study are based on self-reported changes in travel behaviour and travel satisfaction, measured retrospectively (i.e., after people relocated). Memory biases might consequently result in unreliable attempts to recall one's behaviour and satisfaction levels prior to the move (e.g., Mokhtarian \& Cao, 2008). Ideally, people's travel patterns, attitudes and travel satisfaction levels should be asked for before and after a relocation takes place. ${ }^{5}$ However,

\footnotetext{
${ }^{5}$ Note that people evaluate experiences relative to a reference point (e.g., comparing one's current travel pattern to previous travel patterns or to another person's way of travelling) and rate their satisfaction accordingly. Differences in self-reported satisfaction levels at various points in time might consequently be affected by
} 
besides the general lack of longitudinal data in travel behaviour research (but also in many other domains), surveys before and after a relocation are very hard to organise, as it is almost impossible to know when people will relocate. In this regard, longitudinal (national) household surveys with a large sample and multiple waves might be valuable, although these surveys often do not contain detailed questions concerning travel behaviour (e.g., not considering elements like travel attitudes and travel satisfaction). Besides a residential relocation, future studies on travel satisfaction dynamics might also focus on other events possibly disrupting people's travel behaviour, such as important life events (e.g., changing jobs, retiring, having children) or the implementation of new mobility services/interventions, creating new travel opportunities and limitations (e.g., new metro/light rail services, Mobility-as-aService, road pricing, Sustainable Urban Mobility Plans (SUMPs)).

\section{References}

Abou-Zeid, M., Fujii, S., 2016. Travel satisfaction effects of changes in public transport usage. Transportation 43 (2), 301-314.

Abou-Zeid, M., Witter, R., Bierlaire, M., Kaufmann, V., Ben-Akiva, M. 2012. Happiness and travel mode switching: Findings from a Swiss public transportation experiment. Transport Policy 19, 93-104.

Aditjandra, P.T., Cao, J., Mulley, C., 2016. Exploring changes in public transport use and walking following residential relocation: a British case study. Journal of Transport and Land Use 9 (3), 1-19.

Cao, J., Ermagun, A., 2017. Influences of LRT on travel behaviour: A retrospective study on movers in Minneapolis. Urban Studies 54 (11), 2504-2520.

Cao, J., Ettema, D., 2014. Satisfaction with travel and residential self-selection: How do preferences moderate the impact of the Hiawatha Light Rail Transit line? Journal of Transport and Land Use 7 (3), 93-108.

Cao, J., Mokhtarian, P.L., Handy, S.L., 2009. Examining the impacts of residential self-selection on travel behaviour: A focus on empirical findings. Transport Reviews 29 (3), 359-395.

De Kruijf, J., Ettema, D., Dijst, M., 2018. A longitudinal evaluation of satisfaction with e-cycling in daily commuting in the Netherlands. Travel Behaviour and Society. https://doi.org/10.1016/j.tbs.2018.04.003

De Vos, J., 2017. Analysing the effect of trip satisfaction on satisfaction with the leisure activity at the destination of the trip, in relationship with life satisfaction. Transportation. https://doi.org/10.1007/s11116-017-9812-0

De Vos, J., 2018. Do people travel with their preferred travel mode? Analysing the extent of travel mode dissonance and its effect on travel satisfaction. Transportation Research Part A 117, 261-274.

De Vos, J., Ettema, D., Witlox, F., 2018. Changing travel behaviour and attitudes following a residential relocation. Journal of Transport Geography 73, 131-147.

De Vos, J., Mokhtarian, P.L., Schwanen, T., Van Acker, V., Witlox, F., 2016. Travel mode choice and travel satisfaction: bridging the gap between decision utility and experienced utility. Transportation 43 (5), 771-796.

De Vos, J., Schwanen, T., Van Acker, V., Witlox, F., 2013. Travel and subjective well-being: a focus on findings, methods and future research needs. Transport Reviews 33 (4), 421-442.

changes in reference points (e.g., due to a changed travel pattern following a residential relocation) (e.g., AbouZeid et al., 2012). 
De Vos, J., Witlox, F., 2016. Do people live in urban neighbourhoods because they do not like to travel? Analysing an alternative residential self-selection hypothesis. Travel Behaviour and Society 4, 29-39.

De Vos, J., Witlox, F., 2017. Travel satisfaction revisited. On the pivotal role of travel satisfaction in conceptualising a travel behaviour process. Transportation Research Part A 106, 364-373.

Ettema, D., Friman, M., Gärling, T., Olsson, L.E., 2016. Travel mode use, travel mode shift and subjective well-being: Overview of theories, empirical findings and policy implications. In: Wang, D., He, S. (Eds.) Mobility, Sociability and Well-being of Urban Living. Berlin: Springer, pp. 129-150.

Ettema, D., Friman, M., Gärling, T., Olsson, L.E., Fujii, S., 2012. How in-vehicle activities affect work commuters' satisfaction with public transport. Journal of Transport Geography 24, 215-222.

Ettema, D., Friman, M., Olsson, L.E., Gärling, T., 2017. Season and weather effects on travel-related mood and travel satisfaction. Frontiers in Psychology 8 (140), 1-9.

Ettema, D., Gärling, T., Olsson, L.E., Friman, M., Moerdijk, S., 2013. The road to happiness: measuring Dutch car drivers' satisfaction with travel. Transport Policy 27, 171-178.

Grisé, E., El-Geneidy, A., 2018. Where is the happy transit rider? Evaluating satisfaction with regional rail service using a spatial segmentation approach. Transportation Research Part A 114, 84-96.

Handy, S.L., Thigpen, C., 2018. Commute quality and its implications for commute satisfaction: Exploring the role of mode, location, and other factors. Travel Behaviour and Society. https://doi.org/10.1016/j.tbs.2018.03.001

Higgins, C.D., Sweet, M.N., Kanaroglou, P.S., 2018. All minutes are not equal: travel time and the effects of congestion on commute satisfaction in Canadian cities. Transportation 45 (5), 1249-1268.

Jain, J., Lyons, G., 2008. The gift of travel time. Journal of Transport Geography 16, 81-89.

Krizek, K.J., 2003. Residential relocation and change in urban travel. Journal of American Planning Association 69 (3), 265-281.

Lyons, G., Jain, J., Holley, D., 2007. The use of travel time by rail passengers in Great Britain. Transportation Research Part A 41 (1), 107-120.

Páez, A., Whalen, K., 2010. Enjoyment of commute: A comparison of different transportation modes. Transportation Research Part A 44 (7), 537-549.

Mokhtarian, P.L., Cao, X., 2008. Examining the impacts of residential self-selection on travel behavior: a focus on methodologies. Transportation Research Part B 43 (3), 204-228.

Mokhtarian, P.L., Papon, F., Goulard, M., Diana, M., 2015. What makes travel pleasant and/or tiring? An investigation based on the French National Travel Survey. Transportation 42 (6), 1103-1128.

Mokhtarian, P. L., Salomon, I., 2001. How derived is the demand for travel? Some conceptual and measurement considerations. Transportation Research Part A 35 (8), 695-719.

Morris, E.A., Guerra, E., 2015a. Are we there yet? Trip duration and mood during travel. Transportation Research Part F 33, 38-47.

Morris, E.A., Guerra, E., 2015b. Mood and mode: does how we travel affect how we feel? Transportation 42 (1), 25-43.

Ory, D.T., Mokhtarian, P.L., 2005. When is getting there half the fun? Modeling the liking for travel. Transportation Research Part A 39 (2-3), 97-123. 
Redmond, L.S., Mokhtarian, P.L., 2001. The positive utility of the commute: modelling ideal commute time and relative desired commute amount. Transportation 28 (2), 179-205.

Scheiner, J., Holz-Rau, C., 2013. Changes in travel mode use after residential relocation: a contribution to mobility biographies. Transportation 40 (2), 431-458.

Schneider, R.J., Willman, J.L., 2019. Move closer and get active: How to make urban university commutes more satisfying. Transportation Research Part F 60, 462-473.

Singleton, P.A., 2018. Walking (and cycling) to well-being: Modal and other determinants of subjective well-being during the commute. Travel Behaviour and Society. https://doi.org/10.1016/j.tbs.2018.02.005

St-Louis, E., Manaugh, K., van Lierop, D., El-Geneidy, A., 2014. The happy commuter: a comparison of commuter satisfaction across modes. Transportation Research Part F 26, 160-170.

Susilo, Y.O., Cats, O., 2014. Exploring key determinants of travel satisfaction for multi-modal trips by different traveler groups. Transportation Research Part A 67, 366-380.

Tan, J., Zhen, F., Cao, J., Mokhtarian, P.L., 2018. How do passengers use travel time? A case study of Shanghai-Nanjing high speed rail. Transportation 45 (2), 451-477.

Wang, D., Lin, T., 2017. Built environment, travel behavior, and residential self-selection: a study based on panel data from Beijing, China. Transportation. https://doi.org/10.1007/s11116-017-9783-1

Ye, R., Titheridge, H., 2017. Satisfaction with the commute: The role of travel mode choice, built environment and attitudes. Transportation Research Part D 52B, 535-547.

Zhu, J., Fan, Y., 2018a. Commute happiness in Xi'an, China: Effects of commute mode, duration, and frequency. Travel Behaviour and Society 11, 43-51.

Zhu, J., Fan, Y., 2018b. Daily travel behavior and emotional well-being: Effects of trip mode, duration, purpose, and companionship. Transportation Research Part A 118, 360-373. 